\title{
Conceptualizing Social Determinants of Neighborhood Health through a Youth Lens
}

\author{
Elizabeth Benninger ${ }^{1}$ (D) Megan Schmidt-Sane ${ }^{2}$. James C. Spilsbury ${ }^{2}$
}

Accepted: 16 August 2021 /Published online: 24 August 2021

(c) The Author(s), under exclusive licence to Springer Nature B.V. 2021

\begin{abstract}
This study reports on findings from a youth participatory action research of children's well-being and health. We draw upon the Social Determinants of Health framework, including a focus on structural racism and intersectionality, to holistically explore the ways in which youth (ages 13-17) experience multiple forms of marginalization within the neighborhood, and how these experiences influence their well-being outcomes. We employed the data collection techniques of focus group discussion, community mapping, photovoice, and follow-up small group discussions with 14 African American youth in Cleveland, Ohio. Utilizing participatory thematic analysis, the participants established four main thematic categories connected to the neighborhood which have a strong influence on youth health and wellbeing. These categories included: (1) Crime and safety; (2) Housing and the built environment; (3) Social Influence; (4) Community Activities. By involving youth as co-constructors of the research, we elicited perspectives on the pathways between a healthy neighborhood to healthy residents, with implications for future research, policy, and intervention programming aimed at improving the health and well-being of children and youth.
\end{abstract}

Keywords Participatory Action Research - Social Determinants of Health · Children · Youth · Well-being

Elizabeth Benninger

Exb374@case.edu

Megan Schmidt-Sane

mms44@case.edu

James C. Spilsbury

Jcs5@case.edu

1 Case Western Reserve University, Biomedical Research Building, TA200, 2109 Adelbert Rd, Cleveland, $\mathrm{OH} 44106$, USA

2 Case Western Reserve University, Cleveland, OH, USA 


\section{Introduction}

A child's neighborhood environment is comprised of physical, built, social, and historical features, all of which have an impact on child health outcomes. Living in a healthy neighborhood environment has a strong influence on the physical and psychological development of children - both in the short-term as well as over their life course. In contrast, neighborhood environments which are lacking in resources to support health contribute towards child health disparities, defined as inequitable differences in health outcomes for persons under the age of 18. Well-being research has commonly included health as a key indicator of children's well-being, often operationalized through objective measures such as physical functioning, infant mortality rates, the absence of disease, or the achievement of developmental milestones (Cho \& Yu, 2020; Obradovićet al., 2006). Meanwhile, holistic definitions of health conceptualize it to be more than an indicator rather a state of physical, psychological, and social well-being (Cloninger et al., 2011). However, the way in which well-being is conceptualized in children's research is complex and multi-facetted, including a variety of factors interconnected with mental, physical and psychological health (Sabolova et al., 2020). While the holistic definition of health expands the boundaries beyond physical parameters to be inclusive of physical, psychological, and social components of well-being, the vastness in how well-being is defined creates a standard for children's health which becomes challenging to operationalize and measure and nearly impossible to achieve (Leonardi, 2018).

Child well-being researchers have also emphasized how meanings of health and well-being are socially and culturally situated (Fattore et al., 2021; Sabolova et al., 2020). It is therefore essential to understand the influence of the various social contexts and geographical spaces in which children spend their time (Adams \& Savahl, 2015). A recent paradigm shift has refocused research about children to research with or for children that incorporates their subjective experiences, insights, meanings, and descriptions of factors which influence their well-being (Søndergaard \& Reventlow, 2019). However, studies that ask children and youth themselves about their perceptions, including their experiences and understandings of their environment and how it impacts their health and well-being remain limited (Adams \& Savahl, 2015; Andresen \& Fegter, 2011; Benninger \& Savahl, 2016; Dunmire, 2014). We report on findings from a Youth Participatory Action Research (YPAR) study with youth in Cleveland, Ohio to argue that intersectional systems of structural inequities shape the social determinants of health, which in turn, contribute towards their experiences and understandings of health and well-being. We further elicit youth centered strategies for promoting the health and well-being of young people.

\subsection{Intersectionality Framework and Children's Health}

The intersectionality framework provides a means of understanding disparities in children's health and well-being. This framework pays particular attention to the ways in which multiple social group memberships within a specific socio-cultural 
and historical context combine to shape children's experiences (Nadan \& Korbin, 2018). Health disparities within the neighborhood go beyond being a product or outcome of a specific geographical area, but are also influenced by the social arrangement of hierarchy based on characteristics such as race, ethnicity, gender, and age which are maintained through institutional practices, policies, and norms that structure opportunity (Riley, 2018). Within US urban neighborhoods, significant child health disparities exist across racial, ethnic, socioeconomic, and immigration domains (Friel et al., 2015; Ogden et al., 2016).For example, disproportionate exposure of children from lower socio-economic backgrounds to adverse childhood experiences such as abuse, neglect, economic hardship, discrimination, and victimization has been implicated as an important contributor to the health disparities affecting urban communities throughout the United States (Center on the developing child, 2007; Felitti \& Anda, 2010; Shonkoff et al., 2012; Wade et al., 2016). Children from lower socioeconomic backgrounds are more exposed to poor living conditions and are more likely to experience food insecurity, eat unhealthy diets and experience higher levels of dietary-related diseases (Friel et al., 2015). Children who have access to safe places to be active, neighborhoods that are walkable, and local markets that offer healthful food are likely to be more active and to eat more healthful food, behaviors that could improve health and decrease obesity (Sallis \& Glanz, 2006).

\subsection{Social Determinants of Health}

The Social Determinants of Health framework is useful for understanding existing disparities in child health, and it can capture the complexity of children's health and well-being and how it is influenced by the neighborhood environment. The World Health Organization defines the Social Determinants of Health as "the conditions in which people are born, grow, live, work and age (WHO, 2017)." These conditions are inclusive of societal structures, institutions, policies, and distributions of power and resources and are mediated by social interactions. Aligned with the social determinants of health framework, structural racism has been identified to be a key determinant of population health, and, therefore, a focus on it is essential for advancing health equity (Bailey et al., 2017). More specifically, Bailey et al. (2017) defines it to be "the totality of ways in which societies foster racial discrimination through mutually reinforcing systems of housing, education, employment, earnings, benefits, credit, media, health care, and criminal justice (p. 1453)." Building upon this definition, Riley (2018) argues that structural racism must be viewed beyond a determinant, but as a pervasive system of exposure that unevenly distributes the social determinants of health. Neighborhood features such as race, residential segregation, and neighborhood disadvantage become social determinants of health in many contexts because they capture some of the aspects of structural racism (Riley, 2018).

Disparities in child health outcomes in urban neighborhoods are not random, and largely follow historical roots of social and systemic disadvantage which drive inequities in health outcomes. Urban neighborhoods throughout the US have become racialized through centuries of racial hierarchy and the hardships imposed by living 
in impoverished neighborhood environments reinforce racial inequities and the health disparities seen today at the neighborhood level are often a proxy for persisting forms of structural racism (Riley, 2018). A recent systematic review documented the growing body of literature that links social determinants of health, including racial discrimination, to child health outcomes (Priest et al., 2013). Despite this evidence, there is a need to investigate the complex and interconnected pathways between systemic racism, structural disadvantage, and child health outcomes (Held et al., 2020; Priest et al., 2013; Viner et al., 2012). In this paper, we use a social determinants of health framework within a context of structural racism to understand the intersections and impact of contextual neighborhood determinants not only on health outcomes but how these further influence children's perceptions and experiences of their well-being.

\subsection{Youth Participatory Action Research}

YPAR is a form of Participatory Action Research specifically aimed to increase full youth participation in research and social change. This methodology contrasts with the dominant approach in gathering data on children and youth: rely on adult experts. Additionally, there is a general trend in US city planning and public health interventions for these activities to remain driven by individuals external to the target neighborhoods, individuals who are viewed to be the experts when it comes to city planning, public health, and poverty alleviation. This has historically led to decisions being made on behalf of the people for whom they are intended, in effect excluding them from meaningful engagement in the decision-making and planning processes, and further marginalizing community members who have historically been affected by social and structural inequities.

The utility of the YPAR methodology for advancing research related to health equity has shown a significant increase over the past decade. A systematic review of YPAR studies identified 19 prior studies that engaged youth in participatory research on a range of health-related topics (Anyon et al., 2018). Another conceptual review (Ozer et al., 2020) specifically investigating YPAR and health equity highlighted the value of engaging youth in research because their unique expertise is needed for understanding and addressing key issues affecting youth health, development, and well-being. While a number of studies have engaged youth in research on their health and well-being (Anderson, 2020; Anyon et al., 2018; Ozer et al., 2020), these studies largely overlooked the unique and contextual-based findings related to youth's perceptions on their health and well-being.

YPAR within the context of health equity related research focuses on obtaining a data-based, deeper understanding of a community health challenge to guide solutions that promote health equity from the perspectives of youth themselves (Ozer et al., 2020). YPAR with an equity lens challenges traditionally methodological approaches to child health research and intervention development, ensuring that the participation of individuals from historically marginalized populations and communities, especially children and youth, are included in all stages of the research process. The YPAR approach bases its design model on equality between facilitators 
and youth to allow a collaborative co-creation of knowledge through collective introspection and dialogue throughout all stages of the research process, including the translation of the research findings into action.

\section{Study Aims}

Aim One Explore the perceptions of youth related to how experiences of their neighborhood environment shape their health and well-being.

Aim Two Investigate and prioritize youth-centered strategies for creating neighborhood environments which will promote their health and well-being.

\section{Methods}

\subsection{Study Context}

In the context of this study in Cleveland, Ohio, the geographic location of the neighborhood has a tremendous impact on the resources available to support children's health and well-being. This can be linked to the city's long history of racial segregation, racial zoning, and redlining, which greatly limited the resources of African Americans, Latinxs, and other resident minority groups to support their health and well-being (Aliprantis, 2019). What is notable here is how racist policies that perpetuated residential segregation systematically shaped and continue to shape the access and resources individuals have to be healthy and well. Today, the population of Cleveland remains residentially segregated by race, and the neighborhoods with the highest median household incomes are majority white, while the areas with the lowest median household incomes are those comprised of the largest Black and Latinx populations (NEOCANDO, 2019). This trend in racial segregation and health disparities mirrors that of many urban cities in the United States (Krieger et al., 2020; National Community Reinvestment Coalition, 2020).

These structural inequities are further exacerbated in the health outcomes of children in the city. The highest rates of poverty, infant mortality, teenage pregnancy, amongst other concerning child health statistics, fall within the same neighborhoods that were redlined 80 years ago (Reece, 2015). Regarding children's safety, the 2012-2013 HIP-C community health status assessment shed light on a number of contributors to childhood adversity and toxic stress within the city. For example, the city was reported to have a child abuse and neglect rate of almost twice that of the overall county of 11.2 per 1,000 children (Kippes et al., 2013). The violent crime rate is additionally over twice as high as the rate for the county overall and is twenty times higher than the national benchmark. Violence exposure within the home environment is additionally a concern for young people in the city; a review of the data indicates a 2010 domestic violence rate of 1,440 per 100,000 people (Kippes et al., 2013). 


\subsection{Participants and Sampling}

This study formed part of a larger city-wide research project with children and youth ages 8-17 to explore the impact of the neighborhood environment on child and youth health outcomes. Data from this study were collected from September 2019June 2020. As a result of historical and current racialized systems (i.e. education, housing, wealth) within the study's context, the participants faced multiple, intersecting forms of oppression based on race, socioeconomic status, and age. Study participants were sampled from a historically redlined neighborhood Cleveland, $\mathrm{OH}$. Redlining, a term derived from the legal practice initiated in 1934 by the Federal Housing Administration, was a lending practice of rejecting mortgage applications in specific neighborhoods and rated marginalized, racialized neighborhoods with a low grade regarding investment desirability (Bailey et al., 2017). Although redlining is no longer legal, segregation in the housing, education, and labor markets remain pervasive. Today, historically redlined neighborhoods tend to experience greater challenges as it pertains to neighborhood infrastructure and economic opportunity (Bailey et al., 2017). Within our study's neighborhood, 91\% of the residents are African American (Center for Community Solutions, 2014). Two-thirds of the families live in public housing, with a median household income of $\$ 11,483$ and a child poverty rate of $81 \%$, compared to a national average child poverty rate of $22 \%$ (NEOCANDO, 2019).

While neighborhood residents face a variety of barriers for health and well-being, they also have access to a variety of community assets and resources to support the well-being of children, including three elementary schools, one high school, two institutions of higher education, one hospital, two public libraries, one recreation center, and several community centers, grassroots and nonprofit organizations. Participants were identified by means of purposive sampling in partnership with the local recreation center and a community outreach coordinator from a partnering community health center who had been engaged with youth in the community for over 20 years. Information sheets and verbal information sessions were used to recruit the participants. Inclusion criteria included that participants (1) resided or spent significant time (i.e. attend school or community programming) in the participating neighborhood, (2) were between the ages of 13-17 years, (3) were willing to participate in the project. The study participants consisted of 14 African American youth: 5 females and 9 males. Verbal and written consent was obtained from all participants and their guardians. The study received IRB approval from the university where the researchers are based (STUDY20190965).

\subsection{Methodological Approach}

The overarching methodological framework was Youth Participatory Action Research (YPAR). This approach required intentional effort to ensure inclusion and meaningful engagement for our participants from question development to dissemination of findings, with explicit attention to questions of power. 
Prolonged engagement with the youth along with researcher reflexivity became essential aspects of our study design. We started the conversation with the youth within the broad frame of well-being in the early stages of the study (September 2019). This frame was specific enough of a focus to obtain funding and IRB approval for the project, while enabling a wide range of potential topics or issues to be identified by the youth. The members of the research team modified a series of 16 lessons for the project from open source YPAR lesson plans to the context, methods, and topics identified by the youth (Youth Leadership Institute, 2014; YPAR Hub, 2015). These sessions took place at a local youth center December 2019-March 2020. While preliminary research questions were established, the researchers intentionally designed the lessons to broadly explore health and well-being, which allowed for participants to further define their health-related research questions around issues they viewed as important. The participants were also exposed to a variety of research methodologies and were able to select and participate in four research data collection techniques; focus group discussion, community mapping, photovoice, and follow-up small group discussions and to assist with the data analysis and dissemination process. After the initial focus group, several of the youth volunteered to be facilitators and notetakers for the remaining sessions.

\subsubsection{Focus Group Discussion}

Focus group discussion is a valuable method for eliciting young people's responses related to their views and experiences and for complimenting other research techniques (Morgan et al., 2002). It is characterized by a moderator facilitating and engaging a small group discussion between selected individuals regarding the proposed topic (Catterall \& Maclaran, 1997). One advantage of the method is it provides a format for participants to respond to each other's comments and to generate breadth of opinion on a topic. This technique is well-suited to the aims of the study as it promotes the direct interaction and communication with youth, allowing them to respond more freely due to a more relaxed environment and has been successfully utilized in qualitative research with youth (Adams \& Savahl, 2015; Benninger \& Savahl, 2017). A total of three focus group sessions were held with the participants. Consistent with the exploratory design, the focus group interviews followed a semi-structured interview format, with several core questions per group. Session 1 focused on initial discussions on the neighborhood environment and health. These broad questions were: What is it like to live in your neighborhood, what do you value, and what do you find challenging? What does being happy mean to you, and how does the neighborhood impact that? Session two focused on identifying and discussing community issues of priority for the youth. Session three focused on developing strategies for action to improve the health of young people in the neighborhood. The focus group discussions were recorded and transcribed verbatim by two members of the research team. 


\subsubsection{Community Mapping}

Community mapping was used in this study to gain a deeper understanding of the neighborhood environment and how this influenced the participants' health and well-being. During the community mapping session, participants were invited to work individually or as a small group to draw out a map on a large poster board which represented places, spaces, and people within the community that had an influence on their health and well-being. A follow-up discussion took place in which the youth then presented their maps to the group and allowed the group to ask questions. A member of the research team served as the facilitator, probing at the images included on the maps and asking for further explanations on how these images influence the health and well-being of young people in the neighborhood. The community mapping exercise was a useful means of triangulating research data from the focus group discussions and the photovoice sessions.

\subsubsection{Photovoice}

Photovoice is a data collection technique which provides the opportunity for the participants to gain power in the research process through incorporating their personal voice and identifying community and personal priorities through taking photographs and selecting the content of the photos (Carlson et al., 2006). Based on Freirean problem-posing methodology (Freire, 1972), photographs function as a mirror to communities, reflecting everyday social and political realities that impact and shape people's lives (Liebenberg, 2018). The participants in this study were engaged in various activities using photography to stimulate discussions around their wellbeing and their neighborhood. The participants were accompanied by a member of the research team and a youth leader from the community partner organization on a walking tour of a nearby community where the city had recently invested a number of resources in terms of housing, business development, parks, and schools. The rationale for going to an external community was for the youth to have a reference point to compare the built environment within their own neighborhood to other spaces in the city, which stimulated further dialogue and critical reflection. The participants were encouraged to take photos during the walking tour, which captured aspects of health and well-being.

The participants were then instructed to take photos of spaces within their own community, considering spaces, places, and people that make young people happy/ unhappy, safe/unsafe, healthy/unhealthy, spaces that they value, and spaces which they would like to change to improve the health and well-being of young people in their neighborhood. The participants decided to do this individually, rather than as a group, because they wanted to capture a range of people, places and spaces (i.e. school, home, afterschool program, etc.), a group walking tour might have limited coverage of the neighborhood. All photos were printed and used as a basis of two follow-up group discussions where they were asked to comment on the photos and how they related to their lives and experiences of health and well-being. The youth also had the opportunity to reflect on their photos, write a description on their favorite photos, and share this with the group. 


\subsection{Data Analysis}

Participatory thematic sorting of photos, map images, and focus group discussion content took place in full collaboration with the research participants. During each focus group, key ideas and insights were written on large pieces of paper and displayed on the wall for all participants to see and to provide comments. A brief discussion of the insights gleaned from the discussion occurred at the end of each focus group, and detailed field notes of the entire process were taken by members of the research team. During the next phase of the participatory thematic analysis process, the notes on the large paper from previous sessions were again displayed on the wall, along with the community maps and photo images. Participants then reflected and wrote down key words or themes from the images and discussion content onto note cards and collaboratively sorted these into larger thematic categories. The names of the thematic categories were written on large pieces of paper and hung on a large open wall. The next phase included sorting the photo images within these categories by placing them under the appropriate thematic heading on the wall. The researchers then utilized the qualitative data analysis NVivo version 11 (QSR International) to organize and sort field notes and focus group transcripts in order to identify direct quotes and relevant descriptions supporting the themes identified by the youth (see Fig. 1).

Two of the youth participants volunteered to work with the researchers to construct a preliminary report based on the youth's findings, which combined the participatory thematic analysis with direct quotes from the group discussions. Three sessions were then held with the youth to discuss the report and to check for accuracy. Due to the restrictions which were in place because of the COVID-19 pandemic in April 2020, these sessions were held remotely via Zoom web conferencing software. The first session was open to all participants; however, some participants were unable to attend, and others expressed discomfort speaking up in front of the larger group. It was then decided to host two additional small group Zoom discussions with the participants. During all three discussions, the youth were asked if the

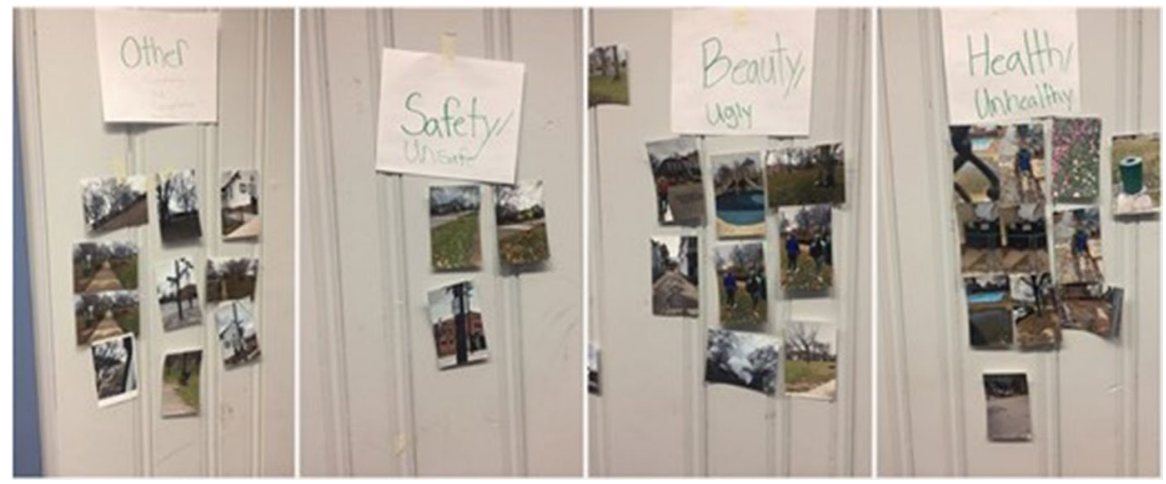

Fig. 1 Participatory Thematic Analysis. This figure provides an image of the sorting of photos by youth during the participatory thematic analysis process 
report captured their ideas and experiences from the research project accurately, and they made additions and changes as needed. The final report was shared with all participants for approval. The findings as co-developed by the youth from the participatory data analysis process are presented in the following section.

\section{Findings}

\subsection{Crime \& Safety}

Crime was described to be one of the most pressing issues identified by the youth because of its impact on most people in the neighborhood. The participants explained how crime makes it unsafe for youth to be outside and to be active. Crime was also described to make it unsafe to be home. Crime also results in young people losing their lives, which impacts mental health and creates stress and anxiety. The participants shared a number of stories related to their experiences of crime, for example:

"I was outside, I was walking from the gas station. Me and my friend, we were riding our bikes. It was the day, you know, <name> got shot. We was all down there, and you know the car, the same car, it came down, it came down speeding, going super fast and ran the red light and stopped in front of us. Kept going, it picked back up its speed, kept going. Stopped in front of the store, let off like four shots and then kept on pushing, and we saw it all. And it was like, all the years that I be living down there, I saw that a lot. Hearing gun shots almost every day, mainly in the summertime. And just see police take people to jail and you hear about police brutality all over the internet." (Male, Age 17, Focus Group Discussion)

"I've watched so many people get arrested, like, at the store all that. The police pulled up and arrested them. Like 12, 13 people at once. I wouldn't want my little brother to see that." (Male, Age 16, Focus Group Discussion).

Crime was additionally mentioned to have a negative impact on local businesses, as exemplified in the following quotation:

"Crime in our neighborhood, mostly crime in our neighborhood results in people having lost lives, 'cause the neighborhood we live in it's kinda rough. Stores getting broken into, and I was saying police should get more involved. Police should be parking in the main parking lot that everybody be at. Where people post up on the corner store and sell they drugs. That won't happen. They'll have to relocate somewhere else." (Male, age 17, Focus Group Discussion)

Solutions identified by the participants to address crime in the neighborhood included increasing police activity that is specifically targeting the hotspots where drug dealers are selling drugs and where they are living. It should not be targeting young people who are not doing anything wrong. Relationships should 
be built between police and young people in the city, where they are on the side of the youth to help fight the crime in the neighborhood and to keep their homes safe. The youth also suggested the police station, currently located on the far east border of the neighborhood, have a more central location in the neighborhood so that response time would be faster. If business owners were better protected from crime, then the neighborhood could attract a variety of businesses (i.e. grocery stores, restaurants, retail, gyms), which they perceived would support their health and well-being. Furthermore, the participants expressed that solutions to address crime in the neighborhood must also focus on addressing poverty, believed to be at the root of the high levels of criminal activity. One way to do this is through providing quality jobs that pay well:

“ 'Cause like the people that's selling drugs, nine times out of ten they can't get jobs and when they do get a job the money coming slow and it ain't a lot, it ain't a lot at all. Dirt cheap. So they feel they making more money even though they risking their life, they're making a lot more money doing this then clocking in at a nine to five job."(Male, Age 17, Focus Group Discussion)

Job opportunities for youth could also decrease crime, because it provides young people with a means of buying the things that they need or want, which parents may be unable to provide, instead of resorting to criminal activity. Jobs can also keep young people busy in a positive way, instead of being outside in a more dangerous environment. This is supported by the following participant quotation:

“...because I have a job I work close to my house, I just go straight home. It's a lot of dangerous stuff happening outside. If I didn't have this job I'd probably be somewhere and I'd probably be killed because they shoot everywhere. They do a lot of stuff everywhere but I'm here. This is one of the activities that I give my attention to and it keeps me out of trouble. If I didn't have a job, I wouldn't be here and I wouldn't do this stuff < referring to activities provided through the recreation center $>$." (Female, Age 15, Focus Group Discussion)

Mixed income housing in the neighborhood was also identified as a solution for addressing crime so that low-income housing would not be so heavily condensed in certain pockets of the city. This needs to be built without removing the existing residents because they can no longer afford the rent and taxes, like has happened in other nearby neighborhoods. Participants also mentioned the need for community events that build trust and bring people together for fun:

"The more they involve the activities and the more we can get together as a community doing stuff. It'd be like people would be more focused. Like every time I'm at a community event, even if I'm in a project in one of the worst neighborhoods, I ain't never been at a community get-together and it's like some crime break out. It's always good, having fun." (Male, Age 17, Focus Group Discussion)

Related to crime in the neighborhood was the need for safety. The youth explained that safety tied most issues related to their health together. In addition 
to safety from the violence, issues around safety included: the need for safer ways for kids to cross the busy roads that run through the neighborhood; and safety in the food that they eat and the food that is available to support their health (see Fig. 2).

\subsection{Housing and the Built Environment}

For the most part the participants spoke about their houses or apartments as good and safe places in the community where they can relax and have some peace. The location, which is close to downtown and other shops and businesses, was also described to be a benefit. In addition to the location, the participants discussed the social benefits of living in apartment complexes, such as being close to all of their friends and having support from their neighbors. In contrast, the social environment was also viewed to be a source of frustration. Several of the youth explained how difficult it was to "keep to yourself" and how people were often gossiping and "creating drama":

Facilitator: What do you like about living there?

Female Participant A (age 15): My bed

Male Participant A (age 14): I know everybody around there

Fig. 2 Photo of safety. This figure is of a photo taken by a participant to capture safety as a factor of child health and well-being

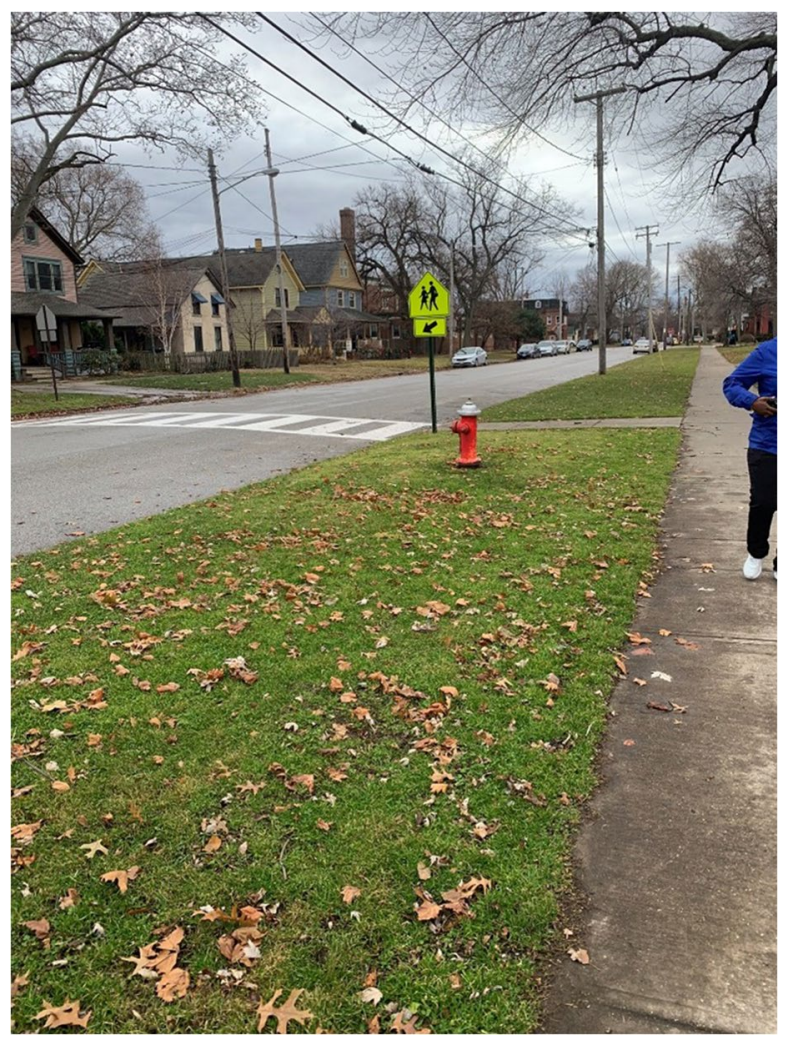


Facilitator: Your bed. You know everybody there.

Female Participant A: Everybody good to me but like....

Female Participant B (age 15): I can tell you what I don't like. All the loud, crazy...

Male Participant A: Gunshots going off!

Female Participant B (age 15): Yeah that's irritating, I hate people. I can't even leave my window open without hearing somebody scream.

Female Participant A: Everybody is always up in your business.

Female Participant B: That's what I don't like!

Interviewer: So you like that you know everybody but at the same time you don't like that everybody is in your business?

Female Participant A: Yeah or people think because you know them and they friends they think "oh you know them, you can talk about them."

Female Participant B: No!

Male Participant A: No, keep that to yourself.

Violence was brought up in the context of housing as well. The youth discussed how they must deal with shooting around their apartments and houses, which makes it unsafe to live there. For example:

"Like I had this dude, he used to live in my building and one day I was in school, I was in the eighth grade, and they had a police standoff in front of my building and I had to stay in school extra long, and like, the police shot him, killed him." (Male, Age 14, Focus Group Discussion)

The youth also discussed the benefits and detriments of other shared community spaces, such as the library, recreation center, and parks. They described the parks, playgrounds, basketball courts, recreation center, and small splash pads to be nice for smaller children in the neighborhood. They also described these shared spaces to be run down and inadequate when compared to other neighborhoods:

Fig. 3 The recreation center. This photo was taken by a youth participant to capture the impact which the recreation center had on youth health. The recreation center was described to have a number of physical and social benefits for health, but also described as being "half done" compared to recreation facilities found in more affluent neighborhoods

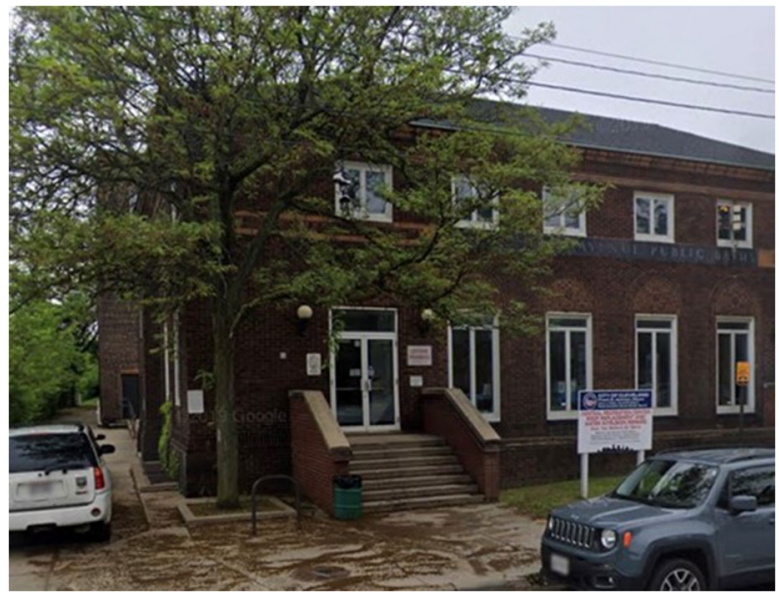


"Like we've got rec centers but everything down here I feel like is just half done (Female, age 16, Photovoice Discussion) (See Fig. 3)."

The library was described to be a socially supportive space for young people with resources to support their learning. Quiet and peaceful spaces were valued and idealized, especially as they compared the noise in their neighborhood to what they observed and valued about other neighborhoods. This value for peace is exemplified in the following discussion of the community maps:

Female Participant C (age 15): I drew this house because it represents me... it represents me because I like being alone. I don't really like nobody. But yeah this is my house I drew it, you see I can draw. It's just plain, 'cause I like quiet, I like peace. I don't want to hear no sirens no nothing.

Male Participant C (age 14): But the city of Cleveland is never quiet.

Facilitator: Do you feel like you have that peace, like when you're at home?

Does it feel peaceful?

Female Participant C: Yeah.

Some solutions identified by the participants to help with the issues related to housing and the built environment included things that young people could do personally, such as not contributing towards social media gossip and surrounding themselves with positive people. They also discussed a need to organize more neighborhood clean-ups and mobilize neighbors to keep the shared spaces clean. It was also suggested to create jobs for people in the neighborhood to clean outside of the housing facilities and in the shared spaces. The participants also suggested building more mixed income housing options so that their neighborhood was not so heavily concentrated with all low-income families. Creating new housing with two- to fourbedroom homes where families can have their own space and yard but with shared common areas could also help with the housing challenges. A similar initiative was already in place in the neighborhood but was not reaching nearly enough families. Living in nicer housing with more space could support the psychological well-being of young people (see Fig. 4). They also recommended building up-to-date recreation centers and a larger water park for the kids. Parks should be inclusive of more

Fig. 4 Community Map. This figure is of a drawing of the housing complex by three participants during the community mapping activity

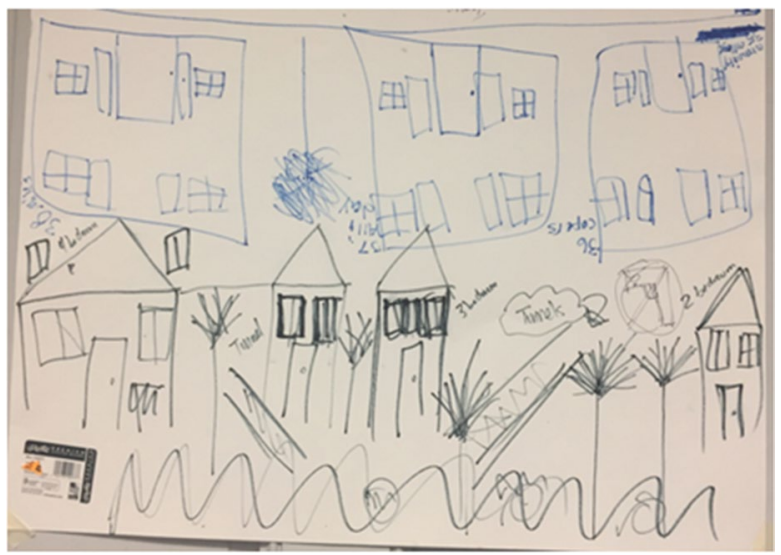


green space with picnic tables and nicer playgrounds. Creating a variety of stores and restaurants in the neighborhood would benefit the residents because it would create more fun spaces for eating, make shopping more accessible, as well as create more local jobs. They mentioned wanting to see places like Whole Foods, Planet Fitness, Popeyes, and Red Lobster in their neighborhood.

\subsection{Social Influence}

Throughout the focus group discussions, the participants focused on the influence which older youth, adults, and their peers have on other young people in the neighborhood. Parents, for example, had a major influence instilling values and feelings of self-worth, along with healthy or unhealthy behaviors, as one participant explains:

"We see a lot of parents like promoting kids to fight. Some of the parents are letting their kids rip around the streets knowing they doing it, and that's not good parenting.... But parents, mmm, parents around here. Like it's not actually where you live, it's how you live. We ain't got a lot of bad parents around here. You got parents that actually care how they live, who actually care how they kids come outside, actually care how they kids conduct themselves. There's certain ones who act like they don't care." (Focus Group Discussion, Male, Age 17)

In addition to the influence which parents had on children and youth, the participants described the influence youth had on other youth and on younger children. For example, youth influenced other youth to get involved in bad behaviors, such as violence associated with the gangs. Even for youth who choose not to join a gang, they can still be influenced by the gang activity, because they are often the victims or witnesses of gang shootings.

“....where we live at in the projects and more like the hood there's a lot of like gang violence going on. And like people around our age group, most of them live down here for years and for a lot of us that's all we see, so this is what some of us adapt to. Unless the ones that want to change that don't want to grow up and be like this. And then another thing like crime rate, I feel that's the big thing around here too 'cause people lose their lives under the age of 18, 21, a lot. You don't get to live to be at least 25, 21. They can't really live how they want to live. They got to worry about walking outside and getting hit with a cross bullet. That's where we live at. You hear gun shots every night" (Youth, age 17, Focus Group Discussion)

Youth were also described to have a positive influence on their peers and on younger children. The participants explained various ways they served as role models for younger children, as illustrated in the following participant quotes:

"If I can like really go every step of the way to actually be an NBA player and the kids from around here, they know it. That could be a good influence on their life. And they can see the money I'm making, see how I can actually love what I'm doing. And then like it will make them want perfection, make them 
want to like get a career job. Even if they want to be a doctor or lawyer or something. They can be something they good at, they can perfect that, it can actually inspire them, then just seeing this all they life." (Male, Age 17, Focus Group Discussion).

"If they see you accomplish your goals then they like "if you can do it, I can do it." Say you make it then you come back, and your actually like supporting your community. Like I can do this, I can do this. Then may say I can probably do this and I can probably do that." (Male, Age 16, Focus Group Discussion)

Solutions for creating positive social influence in the community included developing more mentoring programs where older youth mentor younger children around life skills as well as skills that they excel in, such as sports or reading. They also described the need for more programs that bring parents together with their children around fun activities. These activities could also be used to teach parents how to build healthy relationships with their children. Having healthy and fun activities, such as those provided through the recreation center and the library, will give young people the opportunity to make friends in a safe environment, rather than seeking friends through joining a gang or through participating in unhealthy activities.

\subsection{Community Activities}

Community activities were described to provide new opportunities for youth to be exposed to new people, places, and skills. Community activities also brought people in the community together in a positive way, while also making the environment safer. The following quotes further illuminate the value in community activities:

"If there's more stuff for people to do it will distract the people from doing the stuff that's not really good. It don't have to be activities that's just for one person. It's gotta be stuff that's really gonna get a lot of people engaged because a lot of people around here don't do nothing but stand outside, go in the house, then come back and do it again. Cause they don't have nothing to do." (Female, Age 15, Focus Group Discussion).

"Just like doing activities a lot. Community get more involved together. Yeah that'd stop a lot of violence. Everybody don't got to be worried about a lot of fighting because there's so much fun going on. You could do a lot of stuff, yeah. Then there'd be a lot of parents go out here to see their kids play basketball." (Male, Age 17, Focus Group Discussion)

The participants specifically mentioned activities related to sports, such as basketball, soccer, and football. They also mentioned lifting weights at the recreation center with their peers and mentors. Sports could be used not only as a means of promoting a healthy lifestyle through the physical nature of participation, but also as an opportunity for mentorship and building friendships. Educational activities were also viewed to be important so that kids could be successful in school and in life. Education was viewed as a tool for getting young people out of poverty, however, the youth felt that the schools were not focused on what young people really needed to learn to be successful in their careers and in life more generally. Solutions 
included encouraging government officials and funders to continue to support and value safe spaces in the community, such as recreation centers and libraries, which provided fun activities for young people to develop skills and to build friendships.

\section{Discussion}

\subsection{Summary Findings}

The significance of this study was premised on the idea that youth should be involved in guiding the development of knowledge, policies, programs, and strategies aimed at promoting positive health outcomes for young people in their neighborhood. It therefore placed a strong value on the lived experiences of youth to shape how we understand and conceptualize youth health and well-being, as well as to tailor programs and policies to best fit the youth's context. We utilized a YPAR framework, which is a form of participatory action research modified to ensure youth involvement in research and social change processes. While prior YPAR studies have focused on topics related to youth health and well-being, studies that report on the findings regarding how youth perceive their health and well-being and their strategies for creating health-promoting neighborhood environments remain limited. This study highlights the unique and contextual-based findings related to youth's perspectives on their health and well-being. This required an intentional research design aimed at increasing the power which young people had to participate in the conceptualization and decision-making around place-based issues. In order to achieve this, we drew upon various approaches for data collection which were selected by the youth (i.e. focus group discussion, community mapping, walking tour, photovoice). This provided a useful means of eliciting youths' perspectives on various aspects of the neighborhood environment and deepened our understanding of how these aspects influenced their health and well-being. The design also resulted in developing youth strategies for promoting a healthy neighborhood and for translating the findings from our study into an action plan aimed at improving the health and wellbeing of the neighborhood's children and youth. The next stage of our project aims to implement and evaluate the outcomes and impact of the action plan within the participating community.

\subsection{Youth Perceptions of Neighborhood Determinants of Health and Well-Being}

Health was perceived by the participants to be a complex phenomenon interconnected with various aspects of the neighborhood environment, such as income, housing, social networks, and discrimination, which may be overlooked in other health frameworks. Utilizing participatory thematic analysis, the participants identified multi-dimensional determinants of youth health which impacted their overall well-being. These were organized into four main thematic categories:: (1) Crime and safety; (2) Housing and the built environment; (3) Social Influence; (4) Community Activities. These categories were not viewed to be exclusive of one another, but 
rather interconnected to broader systemic inequities which perpetuated neighborhood poverty, violence, and racial discrimination. For example, crime was described to be socially influenced. The participants explained how easily young people could be drawn into gang-related activities from their peers. They also spoke about the root causes of crime, such as poverty, where limited economic resources within the neighborhood forced people into engaging in criminal activities for their survival. They further described how increasing economic opportunities in the neighborhood could help decrease crime while also creating positive social networks for young people through engaging in work related activities. This would not only have a positive influence on mental health, but would allow people to have the income they need to purchase healthy food or to join a gym with a nice facility.

Another example was found in their perceptions of community activities, which were described to have a positive influence on the physical, social, and psychological health of young people, but at the same time were restricted by high levels of crime in the neighborhood. This created the perceptions that these activities, while important for their health, created an additional risk of violence. Accounts of their experiences of housing and the built environment revealed both positive and negative social experiences that had a mixed influence on their perceptions of health and well-being. For example, people were described to be supportive of one another and to also create extra stress through engaging in gossiping and violence.

In addition to describing various categories of determinants of health and wellbeing within the neighborhood, the youth were aware of the ways that their neighborhood had been historically disadvantaged, and how this influenced the high levels of neighborhood poverty that shaped their current experiences. This perspective aligns with that of Riley (2018), who explains structural racism as a pervasive system of exposure that unevenly distributes the social determinants of health. They were also aware of how intersecting characteristics such as their race, age, and gender created further experiences of marginalization. For example, one participant mentioned his experience of being unfairly questioned by the police while walking around his neighborhood and attributed this to his identity as a young Black male. This experience was affirmed by additional male participants.

The youth also focused their discussions and images on the resources and opportunities within the neighborhood which they perceived to promote health, even when faced with adversity. This included accessing spaces such as the recreation center for exercise and forming positive social networks. Youth employment was also described to have a positive influence on youth and prevented young people from engaging in unhealthy behaviors. Mentorship from older youth and adults within the neighborhood was also identified to promote a healthy sense of self and to influence healthy behaviors, especially for those who were not receiving this type of support from parents. This aligns with the literature on resilience, defined as the processes which promote the capacity of individuals to secure the necessary resources to support their well-being in the face of adversity, and its dependence on the quality of resources available within the neighborhood environment (Ungar, 2012). In this context resilience was only partially viewed to be an internal quality, as seen in descriptions of youth who "choose" to change their life around, but more importantly a process which families, schools, neighborhoods, and policy makers facilitate 
through the allocation of resources, such as high-quality recreation centers, schools, jobs, and social programs, which are accessible to youth to support their health and well-being.

\subsection{Youth Centered Strategies to Promote Health and Well-being}

A focus on decreasing crime and improving safety within the neighborhood was prioritized by the youth due to the central impact it had on their overall health and wellbeing. The perception of various neighborhood spaces as dangerous limited young peoples' ability to engage in health-promoting activities, such as walking or exercising outdoors or to feel safe utilizing various community spaces such as parks and recreation centers, consistent with research on the neighborhood-built environment and its impact on family and child well-being (Haas et al., 2018). It additionally affected their psychological well-being, creating constant anxiety around their personal safety and the safety of family members. Even for environments that were perceived to be safe spaces, such as the home environment, the participants expressed never truly feeling safe because of the way in which crime and violence could happen anywhere. This finding aligns with prior participatory research with children in diverse urban neighborhoods of South Africa challenged by high levels of poverty and structural racism (Benninger \& Savahl, 2016, 2017). The impact which exposure to crime and violence can have on health outcomes across lifespan has been well-documented (Center on the developing child, 2007; Wade et al., 2016), supporting the need for solutions aimed at increasing safety to be essential for improving overall health outcomes.

The participants chose to focus their solutions not only on the symptomatic solutions to poor health outcomes, such as space for physical activity, but additionally recognized the need for addressing the social determinants of ill-health, such as poverty and racial inequality. According to the youth, safety in the neighborhood could be improved only through tackling both the root and immediate causes of crime in the neighborhood. This included creating neighborhoods which had opportunities to various social determinants of health such as education, housing, jobs, and community infrastructure comparable to the wealthier communities surrounding the city. The youth's strategies also pointed to the need for improvements in policing, nicer indoor and outdoor recreational facilities, increased sports and educational activities, positive mentoring and parenting, and fun community events, which would all contribute towards a safer neighborhood environment. These findings provide important implications for policy aimed at improving child well-being and reducing health disparities to center around creating opportunity-rich neighborhood environments which improve various social determinants. Similarly, Held et al., (2020) found that several social determinants of the neighborhood (i.e. economic stability, neighborhood-built environment, and social and community context) are particularly important for adolescent well-being (Held et al., 2020). The findings from Aliprantis (2019) further support the potential in focusing policy efforts on improving neighborhoods and investing in programs that create neighborhood environments for 
children to thrive to reduce existing social, economic, and health inequities, especially within historically disenfranchised Black communities.

\subsection{Limitations}

Study limitations should be noted. Study findings are limited to a case study of 14 youth ages 13-17 years from one neighborhood. Although this small sample was highly informative in generating a meaningful understanding of the perspectives of the participants and their personal experiences and health promoting strategies, the findings in and of themselves cannot be generalized to the larger population. Additional studies which follow a similar design within and across neighborhoods could broaden our understanding of the research topic as well as how the findings from the current study may be applicable or may deviate from the perspectives of young people in other communities and contexts. Also, gathering perspectives from neighborhood children of other age groups would further our understanding of how the neighborhood influences health and may provide insight into the ways in which experiences and perspectives differ from those of older youth and adults. In fact, the next stage of this study will engage children (ages 9-12) and additional youth (ages 13-17) from diverse neighborhoods across the city.

The study's sampling design also presents some additional limitations. The study was formed as a part of a larger university-community partnership with local youth-serving organizations. The researchers and organizational leaders felt it was essential to work directly with established youth programs in order to enhance the work already being done with youth in the city and to ensure the sustainability of the research findings and action plans. The youth from this study were recruited from a youth group hosted by the neighborhood recreation center aimed at providing life and job skills training for young people in the neighborhood. We therefore may have missed important perspectives of other youth in the neighborhood, who for various reasons, were unable or unwilling to participate in the youth group.

Another limitation to the study was in its timing with the COVID-19 pandemic. While most of the data collection took place in person, the final stages were adapted to using Zoom technology due to the county's mandated shelter-in-place orders. This created additional barriers for meaningfully engaging all the participants in the final stages of data analysis and dissemination. Some of the participants struggled to join the Zoom video calls due to barriers in accessing technology, such as not owning a cellphone or computer or having a strong internet connection. Other participants lost interest in engaging in the study through a remote format and reported missing the social aspects of our in-person meetings. In general, the morale of the group was low due to a preoccupation with the global health crisis. We are continuing to work with the participants to further design and implement the youth's strategies for dissemination and action. Further details regarding the action planning and dissemination stages of the project are provided in a manuscript currently in preparation. 


\subsection{Future Research}

Significant areas for future research include measuring if and how youth-centered strategies contribute towards neighborhood environments that promote their health and wellbeing and whether the YPAR process benefits individuals through their participation. YPAR is considered to be a methodological approach which has the potential for a range of benefits for the individual participants as well as for their neighborhoods (Anyon et al., 2018). Outcomes related to personal benefits of YPAR participation have been documented in prior YPAR studies and include improvements in agency, leadership, academic or career, social, interpersonal, and cognitive domains, although there remains a need to provide greater evidence of causality (Anyon et al., 2018). Providing such evidence is challenging, due to the iterative, flexible, and collaborative nature of the YPAR process, which must be adapted to the needs, values, and priorities of the participants.

While a number of additional studies have engaged youth in participatory research on a range of topics related to their health and well-being, conducting a meta-synthesis of the findings would allow for the interpretation of results across multiple studies and the development of an overarching or deeper understanding of youth health and well-being from the perspectives of diverse groups of youth. There remains an additional gap in research which measures the degree to which the information generated by youth through the YPAR process translates into improvements in health and well-being outcomes at neighborhood and policy levels. There is also a need to evaluate the short- and long-term impacts which the study design can have on the health and well-being outcomes of the participants and the broader communities.

While the use of YPAR and other community-based research approaches has increased in health-related research, there remains a need for further research to engage the community members to lay out their vision and drive the changes they would like to see for their own lives and their neighborhoods. These initiatives must be supported by local systems and policies in order to support sustainable changes, to reduce health disparities, and to promote health equity. Likewise, there is a need for further research to measure the impact of interventions targeting multiple intersecting social determinants of health within the neighborhood across the life course.

\section{Conclusion}

This paper reported on findings from a YPAR study of youth well-being and health. A Social Determinants of Health framework, including structural racism and intersectionality, is a holistic way to frame youth health outcomes and underscores the linkage between the neighborhood environment, health, and well-being. By involving youth as co-constructors of the research, we have elicited perspectives on the pathways between a healthy neighborhood to healthy youth with implications for future research on youth well-being and for youth health promotion interventions. 
Acknowledgements The authors acknowledge the youth study participants for their contribution to the study's findings and Jill Korbin for her assistance in writing this paper.

Funding This study received no specific grant from any funding agency in the public, commercial, or not-for-profit sectors. Supplies for the research were provided by the William J. and Dorothy K. O'Neill Foundation (Cleveland, OH, USA).

Data Availability The data that support the findings of this study are available on request from the corresponding author, $[\mathrm{EB}]$. The data are not publicly available due to their containing information that could compromise the protection and privacy of research participants.

\section{Declarations}

Ethics Approval We confirm that we have complied with human subjects research ethical principles in our treatment of individuals participating in the research described in the manuscript. Verbal and written consent to participate in the study and to have the study findings published were obtained by all participants and their guardians. The research has been approved by our institution's IRB (STUDY20190965).

Conflict of Interest/Competing Interests The authors have no relevant financial or non-financial interests to disclose.

\section{References}

Adams, S., \& Savahl, S. (2015). Children's perceptions of the natural environment: A South African perspective. Children's Geographies, 13(2), 196-211. https://doi.org/10.1080/14733285.2013.829659.

Aliprantis, D. (2019). Racial inequality, neighborhood effects, and moving to opportunity. Economic Commentary (Federal Reserve Bank of Cleveland), 2019-17, 1-8. https://doi.org/10.26509/ frbc-ec-201917.

Anderson, A. J. (2020). A qualitative systematic review of youth participatory action research implementation in U.S. High Schools. American Journal of Community Psychology, 65(1-2), 242-257. https://doi.org/10.1002/ajcp.12389.

Andresen, S., \& Fegter, S. (2011). Children growing up in poverty and their ideas on what constitutes a good life: Childhood studies in germany. Child Indicators Research, 4(1), 1-19. https://doi.org/10. 1007/s12187-010-9073-3.

Anyon, Y., Bender, K., Kennedy, H., \& Dechants, J. (2018). A systematic review of Youth Participatory Action Research (YPAR) in the United States: Methodologies, youth outcomes, and future Directions. Health Education and Behavior, 45(6), 865-878. https://doi.org/10.1177/1090198118769357.

Bailey, Z. D., Krieger, N., Agénor, M., Graves, J., Linos, N., \& Bassett, M. T. (2017). Structural racism and health inequities in the USA: Evidence and interventions. The Lancet, 389(10077), 1453-1463. https://doi.org/10.1016/S0140-6736(17)30569-X.

Benninger, E., \& Savahl, S. (2016). The use of visual methods to explore how children construct and assign meaning to the "self " within two urban communities in the Western Cape, South Africa. International Journal of Qualitative Studies on Health and Well-Being, 11(1). https://doi.org/10. 3402/qhw.v11.31251.

Benninger, E., \& Savahl, S. (2017). Children's Discursive Constructions of the 'Self.' Child Indicators Research, 10(4), 899-927. https://doi.org/10.1007/s12187-016-9389-8.

Carlson, E. D., Engebretson, J., \& Chamberlain, R. M. (2006). Photovoice as a social process of critical consciousness. Qualitative Health Research, 16(6), 836-852. https://doi.org/10.1177/1049732306 287525.

Catterall, M., \& Maclaran, P. (1997). Focus group data and qualitative analysis programs: Coding the moving picture as well as the snapshots. Sociological Research Online, 2(1), 41-49. https://doi.org/ $10.5153 /$ sro. 67 . 
Center for Community Solutions. (2014). Cleveland Neighborhoods and Wards - The Center for Community Solutions. https://www.communitysolutions.com/resources/community-fact-sheets/clevelandneighborhoods-and-wards/.

Center on the developing child. (2007). The impact of early adversity on children's development. www. developingchild.harvard.edu/library/.

Cho, E. Y. N., \& Yu, F. Y. (2020). A review of measurement tools for child wellbeing. Children and Youth Services Review, 115 (105576). https://doi.org/10.1016/j.childyouth.2020.105576.

Dunmire, T. (2014). Missing in action. In Quality Progress, 47(9), pp. 52-57. American Society for Quality. https://doi.org/10.7591/cornell/9780801450297.003.0006.

Fattore, T., Fegter, S., \& Hunner-Kreisel, C. (2021) Introduction. In Fattore, T., Fegter, S., \& HunnerKreisel, C. (Eds.). Children's concepts of well-being: Challenges in international comparative qualitative research. pp. 1-18. Springer.

Felitti, V. J., \& Anda, R. F. (2010). The relationship of adverse childhood experiences to adult medical disease, psychiatric disorders and sexual behavior: Implications for healthcare. In The impact of early life trauma on health and disease: The hidden epidemic (pp. 77-87). Cambridge University Press. https://doi.org/10.1017/CBO9780511777042.010.

Freire, P. (1972). Pedagogy of the oppressed. Penguin Books.

Friel, S., Hattersley, L., Ford, L., \& O'Rourke, K. (2015). Addressing inequities in healthy eating. Health Promotion International, 30, ii77-ii88. https://doi.org/10.1093/heapro/dav073.

Held, M. L., Jones, A., \& Forrest-Bank, S. (2020). Predictors of Latinx youth health and emotional wellbeing: Social Determinants of Health Perspective. Journal of Racial and Ethnic Health Disparities, 7(6), 1188-1201. https://doi.org/10.1007/s40615-020-00744-4.

Krieger, N., Van Wye, G., Huynh, M., Waterman, P. D., Maduro, G., Li, W., Gwynn, R. C., Barbot, O., \& Bassett, M. T. (2020). Structural racism, historical redlining, and risk of preterm birth in New York City, 2013-2017. American Journal of Public Health, 110(7), 1046-1053. https://doi.org/10.2105/ AJPH.2020.305656.

Leonardi, F. (2018). The definition of health: Towards new perspectives. International Journal of Health Services, 48(4), 735-748. https://doi.org/10.1177/0020731418782653.

Liebenberg, L. (2018). Thinking critically about photovoice: Achieving empowerment and social change. In International Journal of Qualitative Methods, 17(1). https://doi.org/10.1177/1609406918757631.

Morgan, M., Gibbs, S., Maxwell, K., \& Britten, N. (2002). Hearing children's voices: Methodological issues in conducting focus groups with children aged 7-11 years. Qualitative Research, 2(1), 5-20. https://doi.org/10.1177/1468794102002001636.

Nadan, Y., \& Korbin, J. (2018). Cultural context, intersectionality, and child vulnerability. Childhood Vulnerability Journal, 1(1-3), 5-14. https://doi.org/10.1007/s41255-019-00003-7.

National Community Reinvestment Coalition (2020). "Redlining" and health indicators: Decisions made 80 years ago have health consequences today » NCRC. https://ncrc.org/redlining-and-health-indic ators-decisions-made-80-years-ago-have-health-consequences-today/.

NEOCANDO. (2019). NEOCANDO - Northeast Ohio Community and Neighborhood Data for Organizing. http://neocando.case.edu/.

Obradović, J., van Dulmen, M. H., Yates, T. M., Carlson, E. A., \& Egeland, B. (2006). Developmental assessment of competence from early childhood to middle adolescence. Journal of Adolescence, 29(6), 857-889.

Ogden, C. L., Carroll, M. D., Lawman, H. G., Fryar, C. D., Kruszon-Moran, D., Kit, B. K., \& Flegal, K. M. (2016). Trends in obesity prevalence among children and adolescents in the United States, 19881994 through 2013-2014. Journal of the American Medical Association, 315(21), 2292-2299. https://doi.org/10.1001/jama.2016.6361.

Ozer, E. J., Abraczinskas, M., Duarte, C., Mathur, R., Ballard, P. J., Gibbs, L., Olivas, E. T., Bewa, M. J., $\&$ Afifi, R. (2020). Youth participatory approaches and health equity: Conceptualization and integrative review. American Journal of Community Psychology, 66(3-4), 267-278. https://doi.org/10. 1002/ajcp.12451.

Priest, N., Paradies, Y., Trenerry, B., Truong, M., Karlsen, S., \& Kelly, Y. (2013). A systematic review of studies examining the relationship between reported racism and health and wellbeing for children and young people. Social Science and Medicine, 95, 115-127. https://doi.org/10.1016/j.socscimed. 2012.11.031.

Reece, J. (2015). A Policy Brief Prepared on behalf of the Cuyahoga County PlaceMatters Team. www. CuyahogaPlaceMatters.com. 
Riley, A. R. (2018). Neighborhood disadvantage, residential segregation, and beyond-Lessons for studying structural racism and health. Journal of Racial and Ethnic Health Disparities, 5(2), 357-365. https://doi.org/10.1007/s40615-017-0378-5.

Sabolova, K., Birdsey, N., Stuart-Hamilton, I., \& Cousins, A. L. (2020). A cross-cultural exploration of children's perceptions of wellbeing: Understanding protective and risk factors. Children and Youth Services Review, 110(2020), 104771.

Sallis, J. F., \& Glanz, K. (2006). The role of built environments in physical activity, eating, and obesity in childhood. Future of Children, 16(1), 89-108. https://doi.org/10.1353/foc.2006.0009.

Shonkoff, J. P., Garner, A. S., Siegel, B. S., Dobbins, M. I., Earls, M. F., McGuinn, L., Pascoe, J., Wood, D. L., High, P. C., Donoghue, E., Fussell, J. J., Gleason, M. M., Jaudes, P. K., Jones, V. F., Rubin, D. M., Schulte, E. E., Macias, M. M., Bridgemohan, C., Fussell, J., ... Wegner, L. M. (2012). The lifelong effects of early childhood adversity and toxic stress. Pediatrics, 129(1). https://doi.org/10. 1542/peds.2011-2663.

Søndergaard, E. \& Reventlow, S. (2019). Drawing as a facilitating approach when conducting research among children International Journal of Qualitative Methods 18 https://doi.org/10.1177/16094 06918822558.

Ungar, M. (2012). The Social Ecology of Resilience: A Handbook of Theory and Practice. https://doi.org/ 10.1007/978-1-4614-0586-3.

Viner, R. M., Ozer, E. M., Denny, S., Marmot, M., Resnick, M., Fatusi, A., \& Currie, C. (2012). Adolescence and the social determinants of health. The Lancet, 379(9826), 1641-1652. https://doi.org/10. 1016/s0140-6736(12)60149-4.

Wade, R., Cronholm, P. F., Fein, J. A., Forke, C. M., Davis, M. B., Harkins-Schwarz, M., Pachter, L. M., \& Bair-Merritt, M. H. (2016). Household and community-level Adverse Childhood Experiences and adult health outcomes in a diverse urban population. Child Abuse and Neglect, 52, 135-145. https:// doi.org/10.1016/j.chiabu.2015.11.021.

WHO. (2017). WHO Commission on Social Determinants of Health - final report. World Health Organization. http://www.who.int/social_determinants/thecommission/finalreport/en/.

Youth Leadership Institute. (2014). Youth-Led PhotoVoice Assessment.

YPAR Hub. (2015). http://yparhub.berkeley.edu/.

Publisher's Note Springer Nature remains neutral with regard to jurisdictional claims in published maps and institutional affiliations. 